\title{
A MODEL FOR AN \\ ELECTRONIC INFORMATION MARKETPLACE
}

\author{
Wei Ge \\ School of Business Administration \\ University of Wisconsin - Milwaukee \\ P.O. Box 742 \\ Milwaukee, WI 53201 \\ USA \\ Telephone: +1-847-894-7891 \\ E-Mail: weige@uwm.edu \\ Marcus A. Rothenberger \\ Department of MIS \\ University of Nevada Las Vegas \\ 4505 Maryland Pkwy. \\ Las Vegas, NV 89154-6034 \\ USA \\ Telephone: +1-702-895-2890 \\ E-Mail: marcus.rothenberger@ccmail.nevada.edu \\ Edward Chen \\ Spessart Str. 18 \\ 65812 Bad Soden \\ Germany \\ Telephone: +49-171-4911-356 \\ E-Mail: edchen68@hotmail.com
}

\begin{abstract}
As the information content on the Internet increases, the task of locating desired information and assessing its quality becomes increasingly difficult. This development causes users to be more willing to pay for information that is focused on specific issues, verifiable, and available upon request. Thus, the nature of the Internet opens up the opportunity for information trading. In this context, the Internet cannot only be used to close the transaction, but also to deliver the product - desired information - to the user. Early attempts to implement such business models have fallen short of expectations. In this paper, we discuss the limitations of such practices and present a modified business model for information trading, which uses a reverse auction approach together with a multiple-buyer price discovery process.
\end{abstract}

\section{INTRODUCTION}

Information is being published on the Internet from countless information sources in such unprecedented speed that people can find almost anything online. As the amount of available information and the number of sources increase, however, efficient retrieval and quality assessment become more and more difficult. Although most information on the Internet is available for free, locating it requires substantial effort - sometimes more than what a single information seeker is willing to invest. At the same time, it is equally difficult for an individual information-seeker to assess the credibility and true value of the accessed information. The need for efficient and reliable information retrieval, therefore, may constitute an opportunity for customized information trading. Such a service can build on the existing notion of information intermediaries, which are "e-commerce companies leveraging the Internet to unite buyers and suppliers in a single, efficient virtual marketplace to facilitate the consummation of a transaction" (Grover and Teng 2001). 
The literature has long supported the notion of information intermediaries in an electronic market environment (Bakos 1998, Benjamin and Wigand 1995, Grover and Teng 2001, Lenz et al. 2002, Mahadevan 2000, Rose 1999). Even though the nature of the Internet lends itself to distributing information as a virtual commodity, most information intermediaries reported in the literature are restricted to tangible goods and traditional services such as the sale of books, airlines tickets, and hotel reservations (Grover and Teng 2001, Luking-Reiley 2000, Rohm and Pernul 2000). In addition, most intermediaries treating information as a virtual commodity, such as search engines and product catalogue aggregators, provide only storage and dissemination of meta-information; they don't provide a means to customize information to the individual information seeker's requirements (Mahadevan 2000). The revenues of this line of business, therefore, are primarily generated from advertising or membership/subscription fees, but not from information trading itself. The few exceptions include web service marketplaces (Yarom et al. 2004) and information marketplaces which will be discussed later in this paper; these business models generate their revenue streams from the sale of the virtual commodities. With the economy changing from a focus on the production of physical goods to communication (Schmid 2001), business models involving for-profit dissemination of virtual commodities may continue to gain importance in the future.

Although most information is available for free if retrieved using search engines, the search cost and credibility of non-rated sources may be so high that an information-seeker would rather pay for quality-rated customized information about a specific subject domain. Grover and Teng (2001) classified information intermediaries according to their relationship with buyers and suppliers. Today's widespread search engines maintain an open relationship to both groups. As information intermediaries compete on their ability to deliver information and provide other value-added services to buyers, they would ultimately evolve towards greater buyer affiliation (Grover and Teng 2001). Hence, a new form of information intermediary that provides a mechanism allowing trading of customized information in a similar manner as tangible goods may be a step in this direction.

\section{INFORMATION MARKET}

The online facilitation of information trading cannot be a simple copy of an existing business model developed for tangible goods. The unique cost structure of information requires a different approach to trading. The economics of information production is driven by the electronic dissemination of information goods. This means that although the production of the first copy of the information may be expensive, the cost for the creation of additional copies tends to approximate zero (Rose 1999, Shapiro and Varian 1998). In the context of producing customized information targeted to the information seeker's requirements, an information supplier may spend a substantial amount of time searching, acquiring, and customizing the information, but once he or she has produced the answer, the cost of selling another piece of the same information is close to zero. Nevertheless, the timeliness of information constrains the potential resale value. Depending on the type of information, its value may diminish rapidly if it is out of date.

Qualified information producers who can create quality information in a specialized knowledge domain are often incurring the highest cost (e.g., lawyers, physicians, etc.). The fixed cost for producing this type of information may be more than an individual information consumer is willing to pay. A model must take advantage of the low variable cost of reproducing information to find multiple buyers for high-priced information. 
Meanwhile, the credibility of anonymous information suppliers in a specialized knowledge domain is crucial to information-seekers. There is a need, thus, to investigate how the distinct properties of information can be translated into a suitable business model. In this article, we first discuss the few existing information intermediaries that represent earlier attempts to implement variations of such a business model. We outline their weaknesses and the possible pitfalls of trading information on-line. We will then propose a business model that addresses these issues.

\section{EXISTING INFORMATION INTERMEDIARIES}

Over the past years there have been several attempts to establish electronic markets for customized information trading. Table 1 summarizes existing business models.

AskJeeves.com and FreeAdvice.com are advertisement-based information markets. The revenue for these web sites comes from advertisement, rather than from fees for providing information. Both web sites are subject to two major limitations. First, for an information seeker who is looking for quality answers, the credibility of anonymous information sources is a major concern, which becomes even more critical in a specialized knowledge domain. Second, because of a lack of incentive for information suppliers to provide quality information, many posted questions remain unanswered (over 50 percent of total posted questions).

Table 1: Existing Intermediaries for Custom Information

\begin{tabular}{|l|l|}
\hline Google Answers & $\begin{array}{l}\text { This service allows users to post custom questions on a virtual board } \\
\text { together with the price the user is willing to pay for the answer. Everyone } \\
\text { can access the board and read posted questions and answers. A number of } \\
\text { pre-screened experts can reply to the question if they feel that the } \\
\text { compensation offered meets their needs. Google Answers recommends } \\
\text { setting the price according to the complexity of the question. If the price } \\
\text { offered is too low considering the time it takes to answer the question, } \\
\text { chances are, none of the experts is willing to answer the request. Thus, } \\
\text { there is an incentive to offer the compensation that is appropriate for the } \\
\text { question. The web site charges a US } \$ 0.50 \text { non-refundable listing fee and } \\
\text { retains } 25 \% \text { of the compensation paid to the expert. In addition to the } \\
\text { promised compensation, users can tip the expert who answered the } \\
\text { question; the web site does not retain a percentage of the tip. Users get a } \\
\text { refund if they are not satisfied with the answer; they also rate the expert. } \\
\text { Several poor ratings may cause an expert to be excluded from the service. }\end{array}$ \\
\hline
\end{tabular}




\begin{tabular}{|c|c|}
\hline Inforocket.com & $\begin{array}{l}\text { The service allows users to post questions about various subjects and then } \\
\text { matches these with users who can provide answers. The information } \\
\text { seeker names a price he or she is willing to pay for the answer and the } \\
\text { information suppliers bid to offer answers. Based on ratings and self- } \\
\text { reported expertise, the information seeker selects the most convincing } \\
\text { information supplier to answer the question. The web site charges a } \\
\text { percentage of the transaction price for the service. In addition, an } \\
\text { information store is available for instant purchase of answers generated in } \\
\text { previous transactions. We are arguing that Inforocket's business model } \\
\text { was not sufficiently tailored to the economic properties of information. In } \\
\text { deed, the web site discontinued its service in October 2001. It introduced a } \\
\text { new business model using the new name LiveAdvice.com. }\end{array}$ \\
\hline LiveAdvice.com & $\begin{array}{l}\text { The website allows users to search for experts in various areas. The } \\
\text { experts are available for advice through traditional phone services - } \\
\text { offering recordings and live conversations, both for a fee. The web service } \\
\text { only supports the search for the experts' phone numbers and facilitates a } \\
\text { rating forum; it does not deliver the information. The web site operator } \\
\text { receives a share of the revenues generated through the phone service. } \\
\text { Since 2003, three separate web sites are covering distinct areas based on } \\
\text { the same business model: keen.com for Astrology and Psychics, } \\
\text { ingenio.com for professional advice, and niteflirt.com for } \\
\text { Social/Entertainment contacts. By } 2004, \text { keen.com, ingenio.com and } \\
\text { niteflirt.com have abandoned their information trading approach. The } \\
\text { URLs are now used for other services: keen.com is a psychic web site, } \\
\text { ingenio.com is an advertising network, and niteflirt.com is a traditional } \\
\text { dating site. }\end{array}$ \\
\hline Askjeeves.com & $\begin{array}{l}\text { The website is a popular search engine that provides an additional service } \\
\text { named "Ask Other People", where users can post questions about various } \\
\text { subjects in order to receive free answers from experts. This web site differs } \\
\text { from the business model we are proposing, as revenues do not come from } \\
\text { the Q\&A forum, but through advertising, as it is the case with most search } \\
\text { engines. }\end{array}$ \\
\hline Freeadvice.com & $\begin{array}{l}\text { The website hosts the Ask a Question on Law Forum providing a place for } \\
\text { users to obtain answers to legal questions. The purpose of this web site is } \\
\text { to get users to hire traditional lawyers. The Forum provides simple } \\
\text { answers to attract people to the web site. For more detailed legal help, } \\
\text { lawyer contact information is provided by region. Also, users can post a } \\
\text { legal case to a lawyer that will be selected by the web site provider. The } \\
\text { source of revenue is the advertisement of legal services. }\end{array}$ \\
\hline
\end{tabular}

Inforocket.com was one of the few pay-per-answer services; however, the model did not succeed. After several attempts to refocus the concept, all succeeding web-sites have abandoned their information trading approach and have reverted to more traditional business models (see Table 1). Based on a survey of Inforocket.com during its operation, we found that approximately 400 questions were posted per day and most requests paid about US\$10 with few items up to US\$75. Although Nielsen (2003) predicts that users will be willing to pay for quality content on the Internet in the near future, at present it seems that it is taken for granted that most information on the Internet is free. The lack of 
willingness to pay a higher price for an answer ultimately affects the quality of the information provided. Google Answers is a new commission-based information trading service that started in 2005. Google Answers does not allow for information resale, as it makes past questions and answers freely available. Thus, the user originally posting the question must provide the entire compensation for the expert that answers a question, making quality information expensive. Low-priced questions can hardly attract well-paid professionals with a specialized expertise, such as lawyers or physicians, to spend their time providing an answer. The concern about the quality of answers, consequently, affects the willingness of information seekers to pay for answers and will lead to the relatively small volume of transactions. Although a working resale market for information is desirable in order to maximize compensation for the expert, yet limiting the cost for the individual answer seeker, the Inforocket.com model failed to address that most information is time-sensitive and hence information quality (accurateness, timeliness, relevancy, etc.) changes over time. Answers from previous transactions cannot be updated to keep the information current, thus limiting the potential resale. Figure 1 summarizes the Inforocket.com pay-per-answer information-trading model. We argue that there is potential for an improved business model that addresses above issues.

A variation of a reverse auction model can be employed in the context of information trading. The nature of individual consumer-oriented marketplaces for information trading implies that the information needs of a particular group of information seekers are specific. Hence, information suppliers must know information seekers' requirements before they can provide answers. The value added by information suppliers largely comes from customizing information for a particular group of information seekers. However, there are also some concerns about the reverse auction model. For example, well over $80 \%$ of the product requests were never fulfilled on Priceline.com because the company was not able to find a willing supplier (McClellan 2000). One important implication in Priceline's case is that buyers tend to set the desired prices too low, thus decreasing the chances to get the item requested. Therefore, as we investigate any business models that promise consumer empowerment through a reverse auction, we need to realize that they inevitably involve the risk of a low bid rate. 
Figure 1: Model of a Commission-Based Information Intermediary (Inforocket.com)

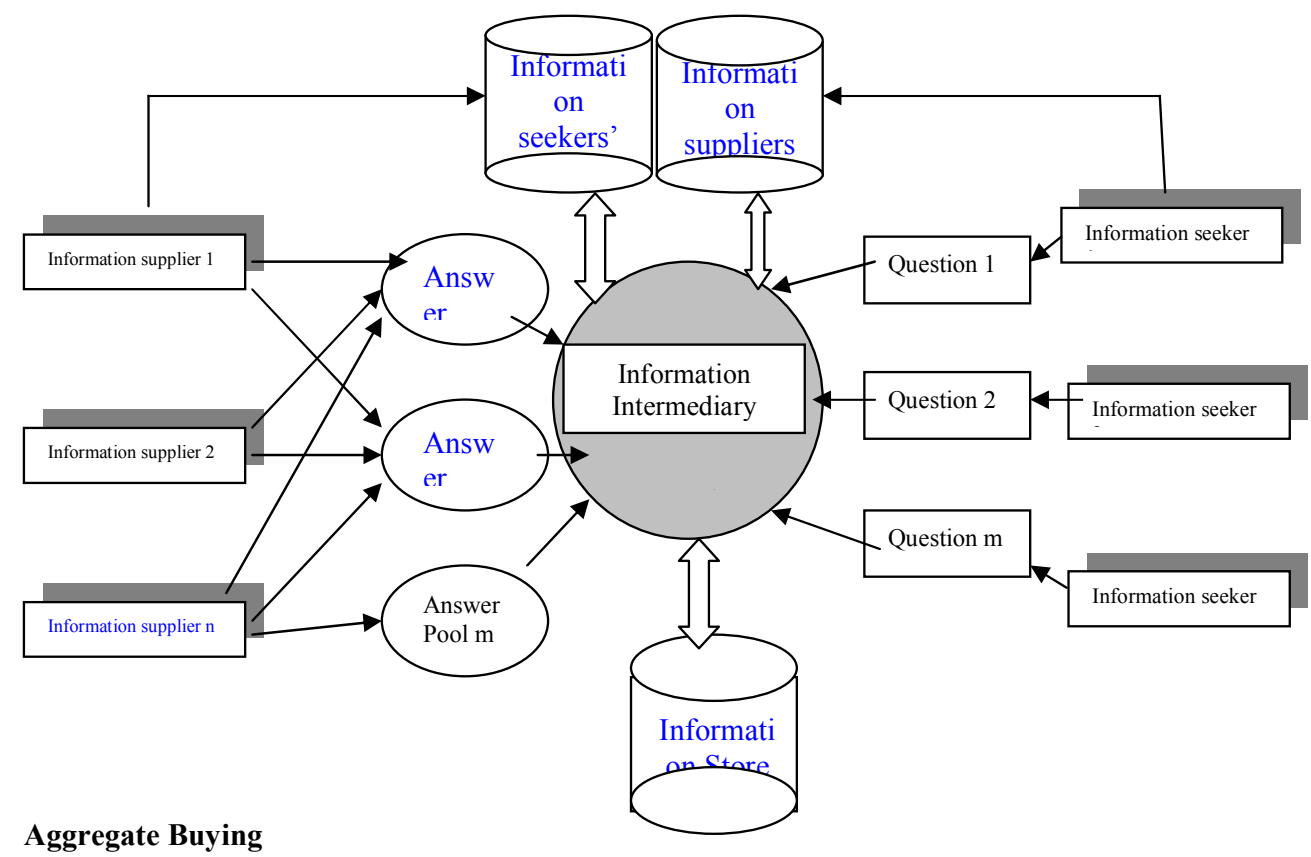

As mentioned above, the questions posted on the Inforocket web site were priced mostly around US\$10. Clearly, the information suppliers with specialized knowledge have little incentive to supply information at such low rates. Rafaeli and Raban (2003) have shown that information sellers typically require a higher price to provide the information, than information buyers are willing to pay; they argue that information trading models must take this into account. Thus, an information intermediary facilitating information trading between individual consumers, must ensure that the price for information attracts individuals or companies with professional knowledge in order to generate a stable revenue stream.

Based on the distinctive cost structure of information, the first copy is expensive, while subsequent copies are cheap (Rose 1999, Shapiro and Varian 1998), there are opportunities to aggregate information seekers and thus minimize a single buyer's cost while increasing the total price of an answer. This works well if the nature of the information is specialized, yet of interest to a group of people (e.g., immigration information relevant to foreigners with a particular visa status in a certain country [provided by a lawyer], information on studies conducted on the effectiveness of a particular medication [provided by a physician], etc.). As information in specialized domains may be of interest to more than one person, such an approach can solve the dilemma between the cost incurred to provide the information and the individual buyers' spending limits. Currently, neither of the two payper-answer business models discussed in this paper (Inforocket and Google Answers) incorporate a mechanism that allows multiple information-seekers to share the cost for an answer. 
We propose that an information seeker can either join an ongoing question or post a new question. An information seeker must provide the maximum amount he or she is willing to pay for the answer, the time window, as well as the minimum acceptable rating of information suppliers. By allowing information-seekers to set the price individually, we address the need for price discrimination for the sale of information goods. Shapiro and Varian (1998) propose to facilitate such price discrimination by offering different versions of the information goods at different price-levels. The ability of the information-seeker in our model to choose the price he or she is willing to pay, before the answer is provided, allows for the implementation of such price discrimination without the need for different versions of the information good. The information-seeker faces a trade-off between offering a low price and being able to obtain the information quickly: the more he or she offers, the sooner the price required for the transaction will be met, as fewer information-seekers must join to meet the price. Thus, an information-seeker has an incentive to offer an amount that is close to the value that the answer represents to him or her, in order to obtain the information without unnecessary delay.

Figure 2: Dynamic Information Pricing

Info- supplier 2

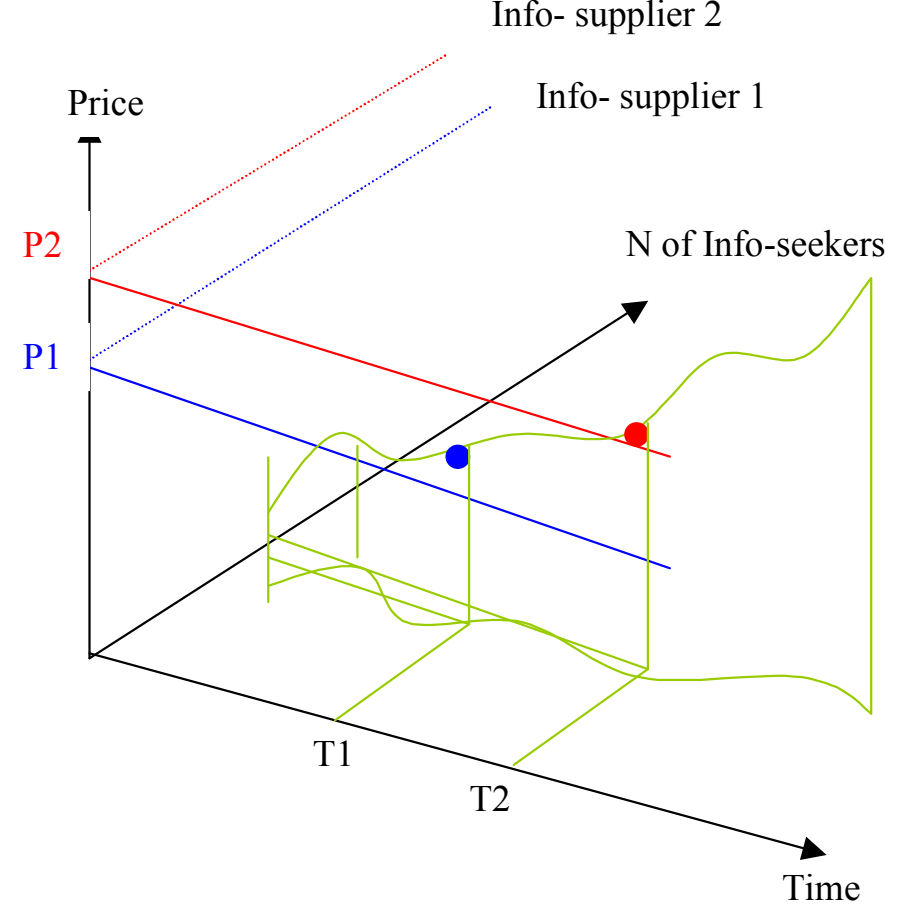


The model is a dynamic pricing system; the final price of an answer is determined by the aggregated price and the minimum requirements for the information suppliers' rating, as specified by all information seekers joining a particular question, the rating, and professional qualification records of available suppliers. When the aggregated price of all information seekers who signed up for a particular question reaches the offer price posted by an information supplier, and if the same information supplier also meets the minimum rating and professional qualification required by the information seekers, the auction closes successfully (Figure 2). If more than one information supplier meets the requirements (both the bid price and the rating) at the same time, then the one with the highest rating wins the bid. Information seekers joining a particular question are required to pay the previously specified amounts to the supplier.

As demonstrated by sites like eBay, and Amazon, the rating system has proved to be an effective way to build trust in a quasi-open market (Luking-Reiley 2000). However, sometimes serious information seekers looking for high quality answers in some specialized domains (such as legal advice) will be putting more stress on the qualifications and reputation of the information suppliers in those particular domains. If this is the case, a rating system alone may not satisfy all the criteria of those information seekers. Thus, in addition to the widely applied rating system in most $\mathrm{C} 2 \mathrm{C}$ auction models, the proposed model requires each information supplier in a specialized domain to provide his or her professional background and sometimes a certification from a third party to prove his or her qualifications in a particular specialized domain in order to enter in a bid for supplying information.

The more people sign up for a particular question, the higher will be the total price that is paid for an answer. The cost for obtaining an answer to the individual information seeker is lowered, while the total revenue for the information supplier is maximized through the aggregation of buyers. Information seekers, information suppliers as well as the information intermediary are all winners. An important implication of the model is that it generates a strong incentive for information suppliers with a professional knowledge base to offer high-priced information. More high-priced quality information such as legal advice, health care information, etc., may generate larger volumes of transactions and hence higher revenue for information intermediaries. Figure 3 summarizes the aggregate buying model.

Figure 3: Aggregate Information Buying Model

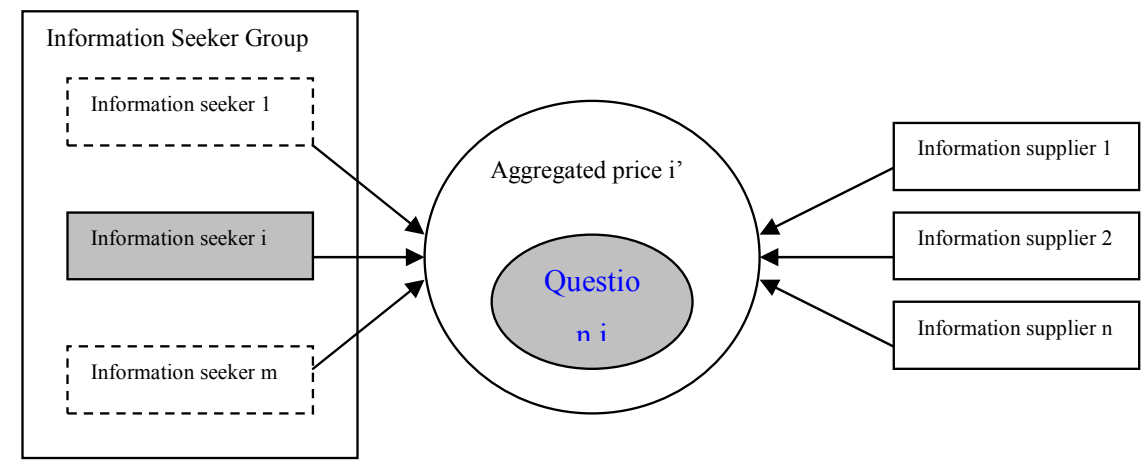




\section{Information Store}

The distinctive cost structure of information also enables the information supplier to generate additional revenue by reselling information that has been generated through previous transactions. Existing information trading models have implemented online stores to allow experts to resell answers they have created in earlier transactions; information seekers can then purchase such information instantly. However, existing models assume that information can be resold with little or without change and do not account for the information quality (accurateness, timeliness, relevancy, etc.) decreasing over time, rendering most information obsolete or outdated within a short time span. Thus, we propose that information suppliers must be able to maintain and modify their answers in the information store. Information suppliers, therefore, will have a strong incentive to update the answers in the information store as updates increase the likelihood of reselling the information.

Information requests usually are specific and unique to a particular group of information seekers. This may imply a low degree of reusability of the information gathered corresponding to some specific questions. However, the same question can be asked in a more general way to increase its resale potential. For example, an information seeker searching for information on immigration information to the United States can phrase her or his questions in different ways:

- "I have applied for an adjustment of status from F1 (Student) to H2B (Temporary Skilled Worker). Can I leave the country while the application is being processed? What documentation will I need to reenter the US?", or

- "Can an alien living in the US leave the country and reenter, while the Immigration and Naturalization Service is processing an adjustment of status? Does it depend on the visa status? If yes, please specify the requirements that must be met to travel outside the US during the adjustment of status process."

The answer to the second question would apply to more potential information seekers than the answer to the first. The second answer may include information on various visa statuses, thus applying to any alien who is changing status. The first question can only attract information seekers that are changing from F1 to H1B status, because it has been phrased in an unnecessarily constraining way.

If an information seeker desires to attract other information seekers for aggregate buying, he or she will post the question in a general fashion. However, if aggregate buying is not in the intention of the information seeker, another incentive is needed to encourage posting a question in a general fashion with a high resale potential. It is in the interest of the information intermediary to maximize the resale likelihood of every posting. Therefore, our model pays a percentage of the resale revenue not only to the information supplier, but also to the information seeker who initially posted the question. This stream of revenue can offer an incentive for information seekers to post more valuable questions, making resale more likely. 


\section{CONCLUSION}

We have discussed the potential of an electronic information marketplace. The review of existing business models has shown that there are several shortcomings in the current practice. We have argued that an information-trading model that incorporates the distinctive cost structure of information can offer a viable alternative to the existing information intermediary strategies that are mostly based on advertising revenue.

Through providing the services of aggregate buying and an information store, the model exploits the potential opportunities created by the high fixed and low variable cost of creating information. While acknowledging the uniqueness of some specific information requests, we have provided concrete examples for specialized information that is of interest to specific groups of users. It is this type of small-scale reusable information for which the proposed model would work best. We are not arguing that the model is a silver bullet for any type of information trading on the web. However, we are arguing that there is a need to expand the existing set of information intermediary models to include pay-per-answer services for specialized subject domains. Although initial attempts at commission-based information intermediaries existed (e.g., Inforocket.com), these early models did not prevail. We have enhanced the existing notion of information trading by linking the unique properties of information to the requirements of such a business model. The authors believe that the model presented in this article may prompt the web community to take a second look at commission-based information trading. Google has recently taken a step in this direction; however, its new Google Answers service neither incorporates an information store nor the concept of aggregate buying.

\section{REFERENCES:}

Bakos, Y. (1998) "The emerging role of electronic marketplaces on the internet", Communications of the ACM, Vol 41 No 8, pp. 35-42.

Benjamin, R. and Wigand, R. (1995) "Electronic markets and virtual value chains on the information superhighway", Sloan Management Review, Vol 36 No 2, pp. 62-72.

Figueiredo, J. M. de. (2000) "Finding sustainable profitability in electronic commerce", Sloan Management Review, Vol 41 No 4, pp. 41-52.

Grover, V. and Teng, J.T.C. (2001) "E-Commerce and the Information Market.", Communications of the ACM, Vol 44 No 4, pp. 79-86.

Lenz, M., Zimmermann, H.-D., Heitmann, M. (2002) "Strategic Partnerships and Competitiveness of Business-to-Business E-Marketplaces: Preliminary Evidence from Europe", Electronic Markets, Vol 12 No 2, pp. 100-111.

Luking-Reiley, D. (2000) "Auctions on the internet: what's being auctioned, and how", The Journal of Industrial Economics, Vol 48 No 3, pp. 227-252.

Mahadevan, B. (2000) "Business models for internet-based e-commerce: an anatomy", California Management Review, Vol 42 No 4, pp. 55-69.

McClellan, J. (2000) "Browsing for buyer power. They are auctions with a twist: you name your price and sellers try to match it." The Guardian, 16 March.

Nielsen, J. (2003) "The Case for Micropayments", http://www.useit.com/alertbox/980125.html, accessed November 2003.

Rafaeli, S. and Raban, D.R. (2003) "Experimental Investigation of the Subjective Value of Information Trading", Journal of the Association for Information Systems, Vol 4, pp. 119-139. 
Rohm, A.W. and Pernul, G. (2000) "COPS: a model and infrastructure for secure and fair electronic markets.” Decision Support Systems, Vol 29, pp. 343-355.

Rose, F. (1999) The economics, concept, and design of information intermediaries. Physika-Verlag, Heidelberg and New York.

Schmid, B. (2001) "What is New About the Digital Economy?", Electronic Markets, Vol 11 No 1, pp. 44-51.

Shapiro, C. and Varian, H.R. (1998) "Versioning: The Smart Way to Sell Information." Harvard Business Review, November-December, pp. 106-114.

Yarom, I., Topol, Z., and Rosenschein, J.S. (2004) "Decentralized Marketplaces and Web Serivices: Challenges and Opportunities", Workshop on Agent Mediated Electronic Commerce VI. 